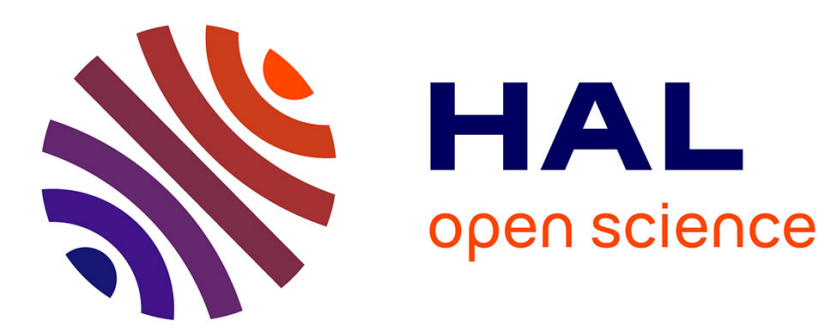

\title{
Unwilling or willing but unable: can horses interpret human actions as goal directed?
}

Miléna Trösch, Emma Bertin, Ludovic Calandreau, Raymond Nowak, Léa Lansade

\section{- To cite this version:}

Miléna Trösch, Emma Bertin, Ludovic Calandreau, Raymond Nowak, Léa Lansade. Unwilling or willing but unable: can horses interpret human actions as goal directed?. Animal Cognition, 2020, 23 (5), pp.1035-1040. 10.1007/s10071-020-01396-x . hal-02993355

\section{HAL Id: hal-02993355 \\ https://hal.science/hal-02993355}

Submitted on 15 Dec 2020

HAL is a multi-disciplinary open access archive for the deposit and dissemination of scientific research documents, whether they are published or not. The documents may come from teaching and research institutions in France or abroad, or from public or private research centers.
L'archive ouverte pluridisciplinaire HAL, est destinée au dépôt et à la diffusion de documents scientifiques de niveau recherche, publiés ou non, émanant des établissements d'enseignement et de recherche français ou étrangers, des laboratoires publics ou privés. 
1 Unwilling or willing but unable: can horses interpret human 2 actions as goal directed?

Social animals can gain important benefits by observing the behaviors of others and inferring the intentions behind these behaviors. Indeed, this ability allows animals to understand and predict the behavior of others and eventually to choose valuable social partners who share the same goal (Call and Tomasello 2008; Woodward 2009; Hauser and Wood 2010). Intentions have been defined as one's goal-directed action, including the goal, the means chosen to achieve it and the rationale behind this means (Buttelmann et al. 2007). Despite its key importance, the ability to infer others' intentions has only been investigated in a handful of nonhuman species (primates: e.g., Call et al. 2004; Buttelmann et al. 2007, 2012; Wood et al. 2007, 2008; Phillips et al. 2009; Canteloup and Meunier 2017; dogs: e.g., Range et al. 2007; parrots: Péron et al. 2010). One of the main paradigms used to study this ability is the unwilling versus unable paradigm. An experimenter performs similar actions, all leading to the same outcome, the subject does not receive the food that is presented, but differing in the intention of the experimenter, i.e., either being unable to give the food or being able but unwilling to do so. Chimpanzees, Capuchin monkeys, Tonkean macaques and grey parrots succeed in this task by reacting differently according to the experimenters' intentions (Call et al. 2004; Phillips et al. 2009; Péron et al. 2010; Canteloup and Meunier 2017).

In the present study, we investigated the ability to infer others' intentions in a species belonging to a different taxon: domestic horses. Horses have a complex social system (Ringhofer et al. 2017) and have been shown to be very sensitive to the behavior of others, including humans (e.g., Krueger et al. 2011; Bernauer et al. 2019; Trösch et al. 2019a; Trösch et al. 2020). For instance, they can infer the current and past attentional state of humans (Proops and McComb 2010; Malavasi and Huber 2016; Trösch et al. 2019b), and some results even suggest that they attribute a knowledge state to humans (Ringhofer and Yamamoto 2016; Trösch et al. 2019b). Horses are thus an interesting species to study the inference of intentions.

We used the unwilling versus unable paradigm: a human experimenter presented a piece of food to a horse but failed to give it for three different reasons. In the unwilling condition, the experimenter refused to give the food and took it back before the horse could reach it. In the unable blocked condition, the experimenter was willing but unable to give the food to the horse because of a physical barrier. In the unable clumsy condition, the experimenter was willing to 
give the food but accidentally dropped it before the horse could reach it. Thus, the intentions of the experimenter differed in the unwilling and willing (but unable) conditions. Our hypothesis was that if horses can infer these intentions, they would react differently in the three conditions, despite the outcome being the same in all conditions. Based on previous results in other species, we expected the horses to show less interest (by turning away from the scene earlier and attracting the attention of the experimenter less) in the unwilling condition than in the two unable conditions.

\section{Materials and methods}

21 horses (8 mares, 12 geldings and 1 stallion) of various ages (Mean $\pm \mathrm{SEM}=11.33 \pm 0.99$ ) and breeds were used. All were kept in a same stable and were privately owned: they lived in stalls with regular access to individual outside paddocks, were fed three times a day with concentrated pellets and hay and had access to water ad libitum.

All procedures were carried out in accordance with the guidelines of the Ethical Committee of the French Ministry of Agriculture that gave us a positive recommendation (protocol number: 20190924-01-MT-CE19).

The horses were tested individually in the same stall ( $3.5 \times 3 \mathrm{~m}$; Fig.1). The window of the stall was covered with a transparent Plexiglas plate $(120 \times 90 \mathrm{~cm})$. The plate contained a small hole $(6.5 \mathrm{~cm}$ in diameter) at a height of $160 \mathrm{~cm}$. This hole could be closed by a transparent Plexiglas disk completely covering the hole except for an opening $(1 \mathrm{~cm}$ in diameter) at the center to allow for olfactory cues. A table $(80 \times 50 \mathrm{~cm})$ was placed outside the door of the stall, below the window.

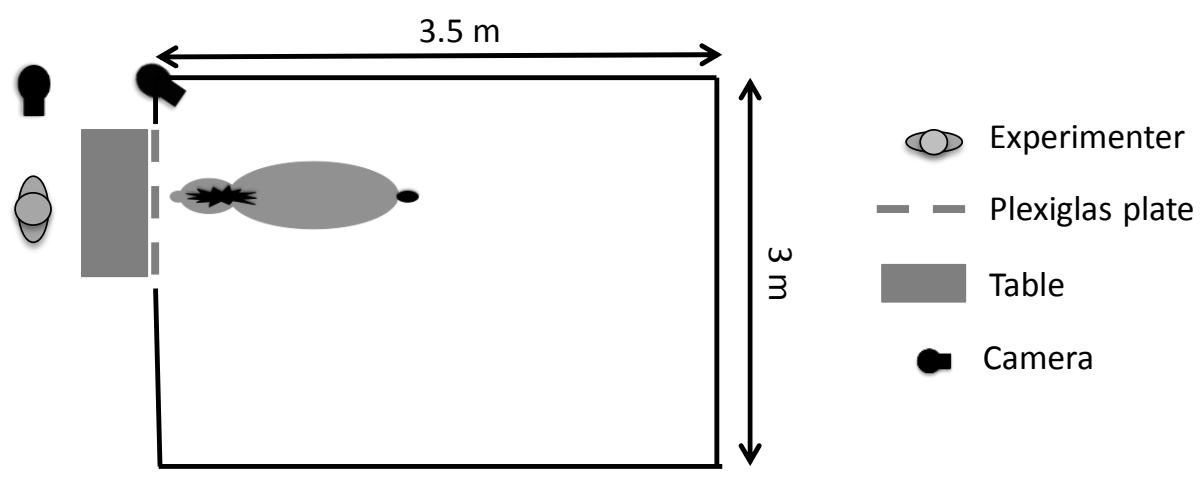

Fig. 1 View of the stall. 
The horses were tested in the morning, in one session carried out in the following manner:

66 Familiarization. The horse was first left alone in the stall for 3 minutes to get familiarized with 67 the situation after which, there was one motivational trial. A trial consisted of the experimenter placing a small piece of carrot on the table for $2 \mathrm{~s}$ and then giving it to the horse through the hole in the Plexiglas plate.

Test. At the end of the trial (when the horse finished eating the piece of carrot), the horse was tested in the three conditions in a counterbalanced order. The three conditions began with a motivational trial and were spaced by 10 -s breaks, during which the experimenter went out of sight of the horse. Each condition consisted of 6 consecutive trials (with no gaps in between) starting and ending with the piece of food on the table (at the same point in the center of the table; Fig. 2 and Fig. S1).

Unwilling-condition. The experimenter put the piece of food on the table, moved it to the hole (stopping just before the piece of food entered the hole) and then put it back on the table, either immediately after the horse tried to take it or after $2 \mathrm{~s}$, whichever occurred first. Unable blocked-condition. The experimenter put the piece of food on the table, brought it to the hole, which was now closed by the transparent disk, and then put it back on the table, either when the horse tried to take it or after $2 \mathrm{~s}$, whichever occurred first.

84 Unable clumsy-condition. The experimenter put the piece of food on the table, brought it to the hole and then accidentally dropped it, either when the horse tried to take it or after $2 \mathrm{~s}$. The experimenter then took the piece of food back to the center of the table before starting a new trial. In every condition, the experimenter looked at the piece of food while picking it up, looked at the horse while bringing the food to the hole and then looked at the food again when bringing it back to the table. The experimenter was instructed to keep a neutral facial expression during the whole procedure. 
Unwilling-condition trial

Plexiglas plate

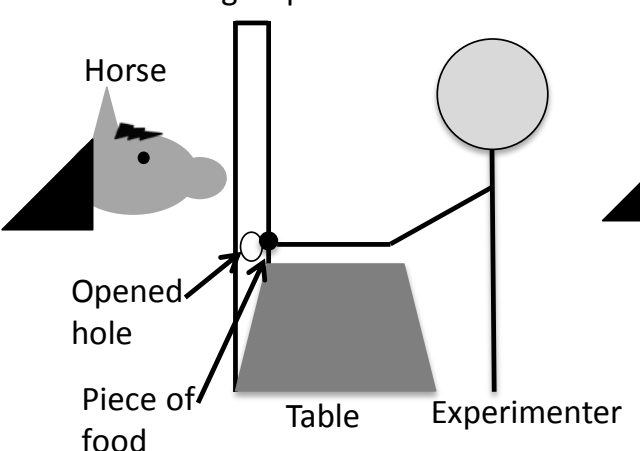

Unable blocked-condition trial (willing)

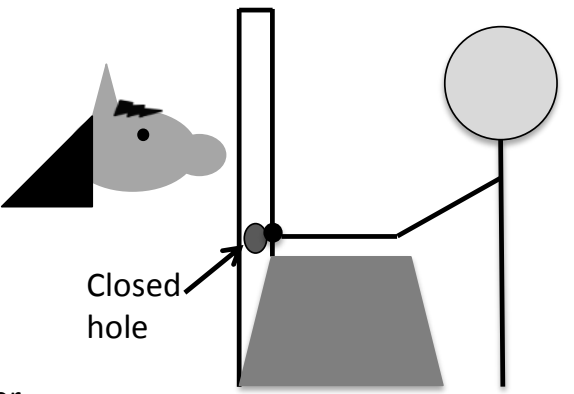

Unable clumsy-condition trial (willing)

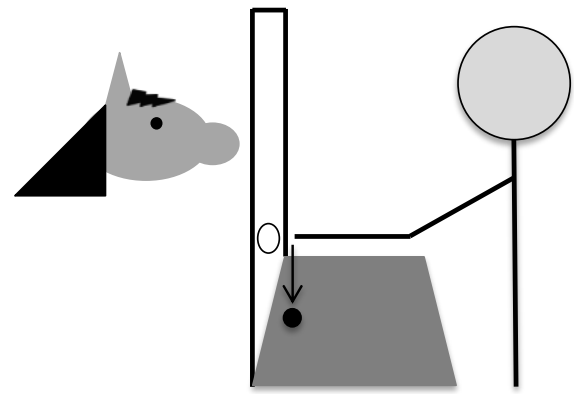

Fig. 2 Schematic representation of the experimental set up.

\section{Video and statistical analysis}

The behavior of the horse was filmed during the entire session by a camera fixed on the above corner of the stall front door (at a height of $150 \mathrm{~cm}$ ), to the right of the horse (Fig. 1). The videos were analyzed using BORIS v. 6.2.3 (Friard and Gamba 2016) for the following behaviors. (1) The percentage of time spent looking at the scene before the horse turned away for the first time during the total duration of each condition. The horse was considered to turn the head away when its muzzle was not directed within $45^{\circ}$ from the center of the Plexiglas plate. Latency is a common measure in the studies using the unwilling versus unable paradigm (Call et al. 2004; Phillips et al. 2009). Here, we chose to use a percentage instead of a simple latency to account for the variation in the duration of the trials. (2) The percentage of time the horse spent touching the Plexiglas plate during the total duration of each condition. This behavior was defined as pressing its nose against the plate without touching the hole (to exclude the times the horse was only trying to take the food through the hole). Touching the Plexiglas plate can be interpreted as a mark of interest for the scene or as an attempt to solicit the experimenter.

Furthermore, the actions of the experimenter during the three conditions were recorded by a camera positioned to the experimenter's left side and at a height of $1 \mathrm{~m}$ (Fig. 1) to ensure that those were consistent between the three conditions. We analyzed the total duration of the trials, the duration of the experimenter's first movement (bringing the piece of food from the table to the horse) and second movement (bringing the piece of food back to the table) and the time the experimenter spent looking at the horse during each trial. 
118 All statistical analyses were performed using R 3.0.2 (R Core Team, 2013). The significance 119 threshold was fixed at 0.05. Concerning the behavior of the horses, both variables were 120 analyzed with a generalized linear mixed model with a Binomial distribution and a logit link 121 function, using a Likelihood ratio test in the 'Imer' function in the lmerTest package 122 (Kuznetsova et al. 2015). For every model, the condition was added as a fixed effect, and the 123 identity of the horse was added as a random effect. We checked for overdispersion and the 124 independence of the observations graphically and assessed the accuracy of our models by 125 calculating the Pearson's correlation between the observed and the predicted values (the accuracy was high for both models: percentage of time spent looking at the scene before looking away for the first time: $\mathrm{r}=0.82, \mathrm{P}<0.001$; percentage of time the horse spent touching the

128 Plexiglas plate: $\mathrm{r}=0.75, \mathrm{P}<0.001)$. Tukey's post hoc analysis was performed using the function 129 "summary.glht" in the multcomp package (Hothorn et al. 2019). Concerning the experimenter's 130 actions, the different variables were analyzed with linear mixed models (using the 'Imer' 131 function): the condition was added as a fixed effect and the identity of the horse as random 132 effect. The normal distribution and homoscedasticity of the residuals were checked graphically 133 and respected the assumptions of parametric analyses for all models.

\section{Results}

136 There was a significant effect of condition on the percentage of time before turning the head away $\left(\mathrm{X}^{2}=65.78, \mathrm{P}<0.001\right)$ and the percentage of time spent touching the Plexiglas plate $\left(\mathrm{X}^{2}=\right.$ $13824.69, \mathrm{P}<0.001)$. The horse spent more time looking at the scene before turning away in the 139 unable clumsy condition (mean $\pm \mathrm{SEM}=52.87 \% \pm 7.61 \%$ ) than in both the unwilling condition 140 (mean $\pm \mathrm{SEM}=40.29 \% \pm 6.87 \% ; \mathrm{Z}=6.20, \mathrm{P}<0.001)$ and the unable blocked condition (mean $141 \pm \mathrm{SEM}=38.37 \% \pm 5.88 \% ; \mathrm{Z}=7.47, \mathrm{P}<0.001 ;$ Fig. 3a). There was no significant difference

142 between the unwilling and unable blocked conditions $(\mathrm{Z}=1.17, \mathrm{P}=0.473)$. The horses spent 143 significantly more time touching the Plexiglas plate in the unable clumsy condition (mean \pm $144 \mathrm{SEM}=17.57 \% \pm 2.85 \%$ ) than in the unwilling condition (mean $\pm \mathrm{SEM}=9.73 \% \pm 2.53 \% ; \mathrm{Z}=$ $1454.89, \mathrm{P}<0.001$ ) and the unable blocked condition (mean $\pm \mathrm{SEM}=13.91 \% \pm 2.33 \% ; \mathrm{Z}=2.34$, $146 \mathrm{P}=0.050$; Fig. 3b). Moreover, the horses spent significantly more time touching this plate in 147 the unable blocked condition than in the unwilling condition $(\mathrm{Z}=2.70, \mathrm{P}=0.019)$. 

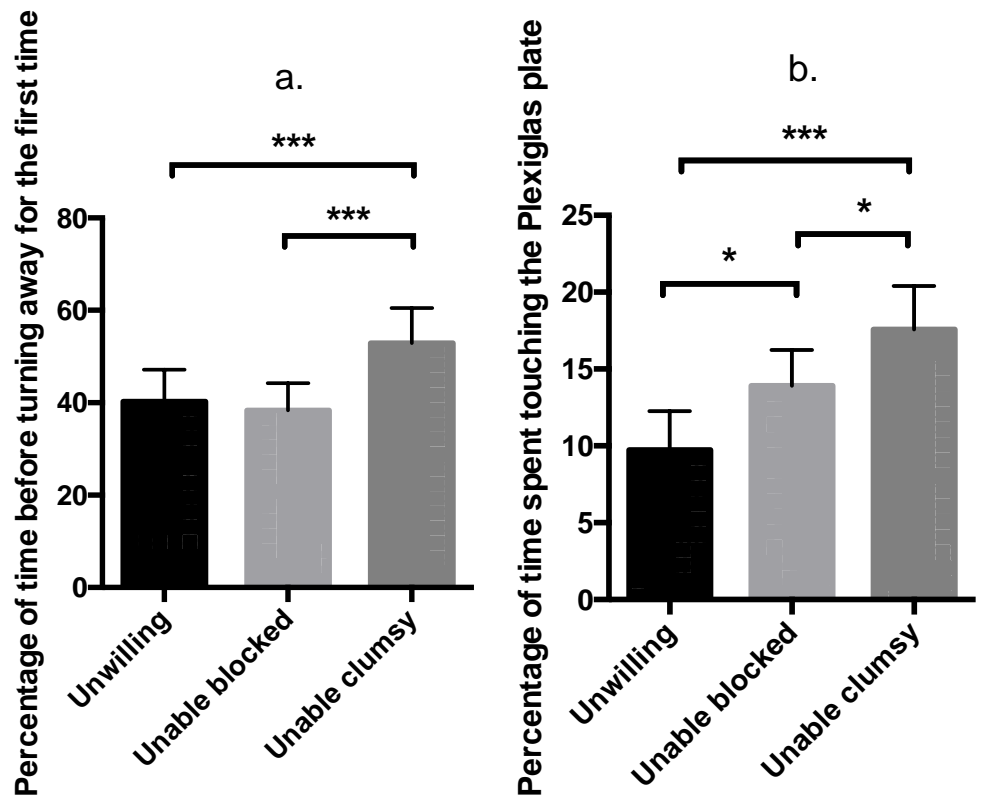

Fig. 3 Behavioral responses during the three conditions: a. Percentage of time spent looking at the scene before turning away for the first time. b. Percentage of time spent touching the Plexiglas plate.

153 The experimenter's actions did not significantly differ between the three conditions, for any of

154 the measured variables (trials duration: $\mathrm{F}=1.36, \mathrm{P}=0.258$; duration of experimenter's first 155 movement: $\mathrm{F}=0.83, \mathrm{P}=0.435$; duration of experimenter's second movement: $\mathrm{F}=2.25, \mathrm{P}=$ 156 0.107; gaze duration towards the horse: $\mathrm{F}=1.33, \mathrm{P}=0.266)$. The means $\pm \mathrm{SEM}$ are given in 157 Table S1.

\section{Discussion}

160 Horses spontaneously discriminated between the three conditions. In the unwilling condition, 161 they spent a lower percentage of time facing the scene before turning away for the first time than in the unable clumsy condition and touched the Plexiglas plate less than in the two other conditions. The percentage of time facing the scene before turning away for the first time is a

164 similar measure to the latency used in previous studies using the same paradigm and was 165 interpreted as an indication of interest (Call et al. 2004; Phillips et al. 2009). Touching the 166 Plexiglas plate could be interpreted as an attempt to solicit the experimenter. In previous 167 studies, horses were found to similarly touch the experimenters as an attention-seeking behavior 168 (Malavasi and Huber 2016; Ringhofer and Yamamoto 2016; Trösch et al. 2019b). Here, horses could not reach the experimenter and might have touched the plate instead. Thus, taken together, our results show that horses expressed less interest in the unwilling than in the two

171 unable conditions. This might be explained by low-level processes or by an understanding of

172 the experimenter's actions as goal directed. 
174 Horses might have used arbitrary cues or have perceived the behavior of the experimenter using 175 low-level behavior reading. The experimenter used gestures that were as similar as possible in 176 the three conditions. For all three conditions, the experimenter interacted with the food, 177 bringing the food to the hole in the Plexiglas plate and bringing it back to the center of the table 178 at the end of the trial. However, there was a slight difference in gesture in the unable clumsy 179 condition as the piece of food was dropped on the table and then brought back to the center, 180 which might have attracted the attention of the horse more compared to the other conditions. 181 Nevertheless, this slight difference in gesture alone cannot explain all our results since we also found a significant difference in behavior between the unable blocked and the unwilling conditions, in which the gestures used by the experimenter were totally identical. A further lowlevel explanation can also be proposed for the difference between the unable blocked and the unwilling condition. Indeed, horses might have behaved differently in the unable blocked condition because they used the blocked hole as a cue that getting the food was impossible (as also suggested in Call et al. 2004; Canteloup and Meunier 2017). In this case, we would have expected them to show more interest when the hole was open (i.e., unwilling condition; Call et al. 2004). However, our results show the opposite, and we thus believe this hypothesis to be unlikely. Moreover, as there was an opening in the disc, the differences observed between the unable blocked condition and the two other conditions are also unlikely to be caused by a difference in olfactory cues.

Horses might also have interpreted the experimenter's actions as goal directed. Their reduced interest in the unwilling condition compared to the two unable conditions could suggest that they have inferred that they would not receive any food because the experimenter did not intend to give it to them. In contrast, in the unable conditions, they could have understood that the experimenter had the intention to give them the food, even though the attempt was unsuccessful. The increased interest of horses in the unable clumsy condition compared to that in the unable blocked condition could be explained by the absence of a physical barrier in the first. Indeed, they might have inferred that the experimenter was more likely to succeed in giving them the food when it was physically possible. Interestingly, our subjects did not show any difference in the percentage of time facing the scene before turning away for the first time between the unable blocked and the unwilling conditions. A potential explanation could be that the horses perceived that they were as unlikely to obtain the food when the experimenter was unwilling to give it and when a physical barrier made the food impossible to reach. Still the horses touched the 
plate significantly more in the unable blocked than in the unwilling condition. This difference

208 between our two variables could be explain by the fact that touching the plate is a more sensitive variable, or because the horses specifically increased this behavior in the blocked condition as an attempt to solicit the help of the experimenter reaching an unreachable food, as it was shown

211 in previous studies (Ringhofer and Yamamoto 2016; Trösch et al. 2019b). Taken together, our

212 results suggest that horses not only perceived the behavior of the experimenter using low-level

213 behavior reading but might also have interpreted the experimenter's actions as goal directed.

214 Hence, they might be capable of inferring at least the lowest level of intentionality, the

215 intentions in action, i.e., the intentions that an individual has while performing an action, as 216 opposed to the more complex prior intentions (Searle 1983). Our results are also consistent with 217 the results found in other species using the same paradigm. For example, Chimpanzees and 218 capuchin monkeys left the test area earlier in the unwilling condition than in the unable 219 conditions (especially in the unable clumsy condition; Call et al. 2004; Phillips et al. 2009). 220 Moreover, Tonkean macaques exhibited less begging behavior toward the experimenter in the 221 unwilling condition than in the unable blocked condition (Canteloup and Meunier 2017).

Interestingly, even though our study was designed to test the social skills of horses, it offers promising preliminary results in terms of physical cognition as well. Indeed, the behavioral differences between the unable blocked and the two other conditions suggest that horses could use the presence of a physical barrier (the disc closing the hole in the unable-blocked condition) between them and the food as an indication that the passage of food was impossible. Hence, that could suggest that they have exhibited causal reasoning about surface continuity, i.e., that objects cannot go through a physical barrier (similar to the "trap-tube" task: Visalberghi and Limongelli 1994; Taylor et al. 2009; Teschke and Tebbich 2011). To our knowledge, this capacity has not been demonstrated in horses as of yet, and further research will be required to confirm this possibility. Horses are thought to have a low visual acuity at short distances (Murphy et al., 2009). Our results suggest that this visual acuity was still sufficient to perceive and respond to visual differences in the three conditions, even though they usually stood at less than $1 \mathrm{~m}$ from the scene. Consistently, previous studies showed that horses can discriminate symbols and even pictures of human faces on a screen while standing very close to the screen (Tomonaga et al., 2015 ; Gabor \& Gerken 2012, 2014 ; Lansade et al., 2020). 
241 To conclude, our study strengthens previous results showing that this species is very sensitive

242 to human behavior. Indeed, horses have been shown to be able to infer the current and past 243 attentional state of humans (Proops and McComb 2010; Malavasi and Huber 2016; Trösch et 244 al. 2019b) and might even infer the knowledge state of humans (Ringhofer and Yamamoto 2016; Trösch et al. 2019b). Our results suggest that horses might also infer human goals or even

246 intentions in action.

\section{References}

Bernauer K, Kollross H, Schuetz A, et al (2019) How do horses (Equus caballus) learn from observing human action? Anim Cogn 23: 1-9. doi: 10.1007/s10071-019-01310-0

Buttelmann D, Carpenter M, Call J, Tomasello M (2007) Enculturated chimpanzees imitate rationally. Dev Sci 10:31-38. doi: 10.1111/j.1467-7687.2007.00630.x

Buttelmann D, Schütte S, Carpenter M, et al (2012) Great apes infer others' goals based on context. Anim Cogn 15:1037-1053. doi: 10.1007/s10071-012-0528-4

Call J, Hare B, Carpenter M, Tomasello M (2004) 'Unwilling 'versus 'unable ': chimpanzees' understanding of human intentional action. Dev Sci 7:488-498. doi: 10.1111/j.1467-7687.2004.00368.x

Call J, Tomasello M (2008) Does the chimpanzee have a theory of mind? 30 years later. Trends Cogn Sci 12:187-192. doi: 10.1016/j.tics.2008.02.010

Canteloup C, Meunier H (2017) 'Unwilling' versus 'unable': Tonkean macaques' understanding of human goal-directed actions. PeerJ 5:e3227. doi: 10.7717/peerj.3227

Friard O, Gamba M (2016) BORIS: a free, versatile open-source event-logging software for video/audio coding and live observations. Methods Ecol Evol 7:1325-1330. doi: $10.1111 / 2041-210 X .12584$

Gabor V, Gerken M (2012) Cognitive testing in horses using a computer based apparatus. Appl Anim Behav Sci 139:242-250. doi: 10.1016/j.applanim.2012.04.010

Gabor V, Gerken M (2014) Shetland ponies (Equus caballus) show quantity discrimination in a matching-to-sample design. Anim Cogn 17:1233-1243. doi: 10.1007/s10071-0140753-0

Hauser M, Wood J (2010) Evolving the Capacity to Understand Actions, Intentions, and Goals. Annu Rev Psychol 61:303-324. doi: 10.1146/annurev.psych.093008.100434

Hothorn T, Bretz F, Westfall P, et al (2019) Multcomp: Simultaneous inference in general parametric models. https://cran.r-project.org/web/packages/multcomp/index.html Krueger K, Flauger B, Farmer K, Maros K (2011) Horses (Equus caballus) use human local 
enhancement cues and adjust to human attention. Anim Cogn 14:187-201. doi: $10.1007 / \mathrm{s} 10071-010-0352-7$

Kuznetsova A, Brockhoff PB, Christensen RHB (2015) lmerTest: Tests for random and fixed effects for linear mixed effect models. http://cran.r-project.org/package1/4lmerTest

Lansade L, Colson V, Parias C, et al (2020) Female horses spontaneously identify a photograph of their keeper, last seen six months previously. Sci Rep 10:6302. doi: $10.1038 / \mathrm{s} 41598-020-62940-\mathrm{w}$

Malavasi R, Huber L (2016) Evidence of heterospecific referential communication from domestic horses (Equus caballus) to humans. Anim Cogn 19:899-909. doi: 10.1007/s10071-016-0987-0

Murphy J, Hall C, Arkins S (2009) What horses and humans see: A comparative review. Int J Zool. doi: 10.1155/2009/721798

Péron F, Rat-fischer L, Nagle L, Bovet D (2010) 'Unwilling' versus 'unable’: Do grey parrots understand human intentional actions? Interact Stud 11:428-441. doi: 10.1075/is.11.3.06per

Phillips W, Barnes JL, Mahajan N, et al (2009) "Unwilling” versus "unable”: Capuchin monkeys' (Cebus apella) understanding of human intentional action. Dev Sci 12:938945. doi: 10.1111/j.1467-7687.2009.00840.x

Proops L, McComb K (2010) Attributing attention: the use of human-given cues by domestic horses (Equus caballus). Anim Cogn 13:197-205. doi: 10.1007/s10071-009-0257-5

Range F, Viranyi Z, Huber L (2007) Selective Imitation in Domestic Dogs. Curr Biol 17:868872. doi: 10.1016/j.cub.2007.04.026

Ringhofer M, Inoue S, Mendonça RS, et al (2017) Comparison of the social systems of primates and feral horses: data from a newly established horse research site on Serra D’Arga, northern Portugal. Primates 58:479-484. doi: 10.1007/s 10329-017-0614-y

Ringhofer M, Yamamoto S (2016) Domestic horses send signals to humans when they face with an unsolvable task. Anim Cogn 20:397-405. doi: 10.1007/s10071-017-1074-x

Searle JR (1983) Intentionality: An Essay in the Philosophy of Mind. Cambridge University Press, Cambridge, UK

Taylor AH, Hunt GR, Medina FS, Gray RD (2009) Do New Caledonian crows solve physical problems through causal reasoning? Proc R Soc B Biol Sci 276:247-254. doi: 10.1098/rspb.2008.1107

Teschke I, Tebbich S (2011) Physical cognition and tool-use: Performance of Darwin's finches in the two-trap tube task. Anim Cogn 14:555-563. doi: 10.1007/s10071-011- 
0390-9

310 Tomonaga M, Kumazaki K, Camus F, et al (2015) A horse's eye view: Size and shape discrimination compared with other mammals. Biol Lett 11:20150701. doi: $10.1098 / \mathrm{rsbl} .2015 .0701$

Trösch M, Cuzol F, Parias C, et al (2019a) Horses categorize human emotions cross-modally based on facial expression and non-verbal vocalizations. Animals 9:862-872. doi: 10.3390/ani9110862

Trösch M, Ringhofer M, Yamamoto S, et al (2019b) Horses prefer to solicit a person who previously observed a food-hiding process to access this food: A possible indication of attentional state attribution. Behav Processes 166:103906. doi: 10.1016/j.beproc.2019.103906

Trösch M, Pellon S, Cuzol F, et al (2020) Horses feel emotions when they watch positive and negative horse-human interactions in a video and transpose what they saw to real life. Anim Cogn. doi: 10.1007/s 10071-020-01369-0

Visalberghi E, Limongelli L (1994) Lack of comprehension of cause-effect relations in toolusing capuchin monkeys (Cebus apella). J Comp Psychol 108:15-22. doi: 10.1037/07357036.108.1.15

Wood JN, Glynn DD, Hauser MD (2008) Rhesus monkeys' understanding of actions and goals. Soc Neurosci 3:60-68. doi: 10.1080/17470910701563442

Wood JN, Glynn DD, Phillips BC, Hauser MD (2007) The perception of rational, goaldirected action in non-human primates. Science 317:1402-1405

Woodward AL (2009) Infants' grasp of others' intentions. Curr Dir Psychol Sci 18:53-57. doi: 10.1111/j.1467-8721.2009.01605.x

Authors:

Miléna Trösch · Emma Bertin · Ludovic Calandreau - Raymond Nowak · Léa Lansade 
